\title{
Soil Ethics: A New Look at Life on Soil
}

\section{Katsuyuki Minami*}

Kitasato University, Japan

*Corresponding Author: Katsuyuki Minami, Kitasato University, Japan.
Received: June 16, 2021

Published: June 29, 2021

(C) All rights are reserved by Katsuyuki

Minami.
More than 50 years have passed since everything changed. That was in 1969. We humans first saw ourselves in the TV screen of the blue Earth from the Apollo spacecraft, like seeing oneself reflected in the surface of flowing river. After that incident, we humans came to the understanding that we cannot separate ourselves from Earth as a whole. And it seems we humans expanded the subconscious awareness that probably Earth is one big living organism in the solar system.

Also, 1969 was a creative year when J.E. Lovelock came up with the awareness that Earth is the biggest organism in the system, what is named GAIA hypothesis. The hypothesis stated that the biosphere has a self-regulating function with the ability to maintain our planet's health by controlling the chemical, physical, and biochemical environment. Because the most advanced science and technology of the Apollo mission at that time had developed consciously and rationally, we gathered and concentrated on seeing Earth as a whole from a bird's-eye view. This guided to the organization of the IPCC (Intergovernmental Panel on Climate Change) and the participation of many scientists in climate change research. The advanced science and technology developed to the topic of receiving the Nobel Prize.

On the one side, while the Gaia hypothesis is also conscious and rational, one distinguishes an unconscious, subconscious, and intuitive background to a small degree. This GAIA hypothesis has had a great influence on not only many engineers and scientists but also religious leaders and educators and so for approaching current problems concerning Earth. Therefore, many scholars, engineers, and others cooperated in integrating and consolidating their knowledge.
A long time has passed since an abnormality occurred in the soil where living things have grown from old times to now, and into the future. This soil change like erosion, pollution, excess chemicals, and so is largely due to the activities of the human sphere since the Industrial Revolution. The pressure of the human sphere has been a great influence on the pedosphere, biosphere, hydrosphere, troposphere, and stratosphere that make up the global environment.

Further, soil is also closely connected to the culture and civilization of an ethnic group living in each place, including their religion, thoughts, custom, livelihood, and health. Soil is extremely important to all people living in the Earth's biosphere. Therefor, it is important for people to conserve the soil, their agriculture, and the environment because the collapse of soil leads to the collapse of human culture, civilization, livelihood, and health [1]. To conserve the events, we must have ethics for the soil.

An ethical relationship with the soil cannot be established without esteem respect and love for the land and soil. Many of us no longer have such a warm intimate relationship with the land and soil. If this is the case, we humans must prove and demonstrate that myths enshrining the soil as God and sprit are still alive, and that ethics for land and soil must be restored.

The time has come to promote a new paradigm for promoting the concept that soil is alive as the subsystem of GAIA. Soil is generally defined as a natural body formed in response to factors including climate, living things, parent material, topography, and time. However, in order to restore land and Earth, it is necessary to recognize that soil is alive like organisms. For that purpose, I demonstrated that soil is alive based on J.G. Miller's Living Systems Theory [2]. 
Many wise men have steadily explained that soil collapse definitely leads to the collapse of civilization. The links between the soil and culture, civilization, livelihood, and health may result from the ethical attitudes that people have about the soil, and that they demonstrate through their interactions with it [1]. However, unless we have ethics and respect for the soil, the end of civilization awaits again. As one of the propositions to overcome this, I would like to emphasis that soil is a living substance $[3,4]$.

\section{Bibliography}

1. Minami K. "Soil and Humanity". Soil Science and Plant Nutrition 55 (2009): 603-615.

2. Minami K. "Soil is a living substance". Soil Science and Plant Nutrition 67 (2021): 26-30.

3. Lovelock JE. GAIA: A new look at life on Earth, Oxford University Press (1979).

4. Miller JG. Living Systems, University Press of Colorado (1993).

\section{Volume 5 Issue 7 July 2021}

CC All rights are reserved by Katsuyuki Minami. 